Clarissa Moschiar Fontelles

\title{
Estudo das propriedades eletrocinéticas e de espectroscopia no campo do infra- vermelho da estirpe R. Ruber na presença de cátions metálicos
}

Dissertação de Mestrado

Dissertação apresentada como requisito parcial para obtenção do título de Mestre pelo Programa de Pós-graduação em Engenharia de Materiais e de Processos Químicos e Metalúrgicos do Departamento de Engenharia de Materiais do Centro Técnico Científico da PUC-Rio.

Orientador: Prof. Mauricio Leonardo Torem 
Clarissa Moschiar Fontelles

\section{Estudo das propriedades eletrocinéticas e de espectroscopia no campo do infra- vermelho da estirpe R. Ruber na presença de cátions metálicos}

Dissertação apresentada como requisito parcial para obtenção do título de Mestre pelo Programa de Pósgraduação em Engenharia de Materiais e de Processos Químicos e Metalúrgicos do Departamento de Engenharia de Materiais do Centro Técnico Científico da PUC-Rio. Aprovada pela Comissão Examinadora abaixo assinada.

Prof. Mauricio Leonardo Torem Orientador e Presidente Departamento de Engenharia de Materiais - PUC-Rio

Dr. Antonio Gutiérrez Merma Departamento de Engenharia de Materiais - PUC-Rio

Prof. Eduardo de Albuquerque Brocchi Departamento de Engenharia de Materiais - PUC-Rio

Profa. Luciene Stivanin Garcia Instituto Estadual do Ambiente (INEA)

Prof. José Eugênio Leal Coordenador Setorial de Pós-Graduação do Centro Técnico Científico da PUC- Rio

Rio de Janeiro, 10 de setembro 2014. 
Todos os direitos reservados. É proibida a reprodução total ou parcial do trabalho sem autorização da universidade, do autor e do orientador.

Clarissa Moschiar Fontelles

Graduou-se em Engenharia Ambiental na Universidade Severino Sombra em 2012.

Ficha Catalográfica

Fontelles, Clarissa Moschiar

Estudos das propriedades eletrocinéticas e de espectroscopia no campo do infra-vermelho da estirpe Rhodococcus ruber na presença de cátions metálicos / Clarissa Moschiar Fontelles; orientador: Mauricio Leonardo Torem. - 2014. 122 f. : il. (color.) ; $30 \mathrm{~cm}$

Dissertação (mestrado)-Pontifícia Universidade Católica do Rio de Janeiro, Departamento de Engenharia de Materiais, 2014.

Inclui bibliografia

1. Engenharia de materiais - Teses. 2. Efluente líquido. 3. Metais pesados. 4. Rhodococcus ruber. 5. Potencial zeta. I. Torem, Mauricio Leonardo. II. Pontifícia Universidade Católica do Rio de Janeiro. Departamento de Engenharia de Materiais. III. Título. 


\section{Agradecimentos}

Ao meu orientador Mauricio Leonardo Torem pelo apoio, paciência, compreensão, sugestões, conselhos e confiança depositados durante a realização deste trabalho.

Ao CNPq e PUC-Rio pelo auxílio financeiro concedido.

Aos Amigos Antonio e Ronald por toda paciência, força, conselhos e orientações durante a realização deste trabalho.

Aos meus colegas e amigos, em especial a Elaynne, da PUC-Rio, aos professores, pesquisadores e funcionários do Departamento de Engenharia dos Materiais e Processos Químicos e Metalúrgicos da PUC-Rio pelos ensinamentos e valiosas sugestões durante a realização deste trabalho.

Ao Daniel, Aline, Paula, Carol, Camila, Ricardinho e Rafael que me incentivaram e me deram força em momentos cruciais durante a realização deste trabalho.

A minha família por todo apoio, confiança, compreensão e carinho.

E em especial a Deus, que me guia todo tempo e que me proporcionou chegar até aqui. 


\section{Resumo}

Fontelles, Clarissa Moschiar; Torem, Mauricio Leonardo. Estudo das propriedades eletrocinéticas e de espectroscopia no campo do infra-vermelho da estirpe $R$. Ruber na presença de cátions metálicos. Rio de Janeiro, 2014. 122p. Dissertação de Mestrado - Departamento de Engenharia de Materiais, Pontifícia Universidade Católica do Rio de Janeiro.

Neste estudo, as propriedades bacterianas da estirpe Rhodococcus ruber in natura e ativada com $\mathrm{NaOH} 0,1 \mathrm{M}$, foram analisadas. $\mathrm{O}$ estudo avaliou a influência dos cátions metálicos $\left(\mathrm{Al}^{3+}, \mathrm{Cr}^{3+}, \mathrm{Fe}^{3+}, \mathrm{Co}^{2+}, \mathrm{Mg}^{2+} \mathrm{e}\right.$ $\mathrm{Ni}^{2+}$ ) sob o comportamento da estirpe bacteriana, no intervalo de concentração entre $10^{-3}$ a $10^{-6} \mathrm{~mol} / \mathrm{L}$. As amostras bacterianas foram caracterizadas por espectroscopia na faixa do infra-vermelho com transformada de Fourier (FTIR). O ponto isoelétrico (PIE) da estirpe $R$. Ruber foi obtido através das análises de potencial zeta. Os resultados demonstraram um PIE com $\mathrm{pH}=2,4$ para a estirpe in natura, já quando ativada com $\mathrm{NaOH}$ 0,1M ○ PIE não foi evidenciado. A superfície bacteriana da estirpe ativada se apresentou levemente mais negativa do que a superfície da bactéria in natura. Para todas as amostras, observouse alteração no potencial zeta durante a interação bacteriana com os íons estudados. Os resultados não apresentam diferenças significativas entre a bactéria in natura e ativada. As amostras permaneceram carregadas negativamente nos $\mathrm{pH}$ estudados, para todos os cátions, exceto $\mathrm{Fe}^{3+}$. Por fim, diante dos resultados apresentados, acredita-se que a estirpe Rhodococcus ruber é uma opção viável para estudos voltados ao tratamento de efluentes contaminados por metais.

\section{Palavras-chave}

Efluente líquido; metais pesados; Rhodococcus ruber; potencial zeta. 


\section{Abstract}

Fontelles, Clarissa Moschiar; Torem, Mauricio Leonardo (Advisor). Studies of the electromagnetic properties and spectroscopy in the infra-red field of $R$. Ruber strain in the presence of metal ions. Rio de Janeiro, 2014. 122p. MSc. Dissertation - Departamento de Engenharia de Materiais, Pontifícia Universidade Católica do Rio de Janeiro.

In this study, the Rhodococcus ruber bacterial strain properties of in nature and activated with $0.1 \mathrm{M} \mathrm{NaOH}$ were analyzed. The study evaluated the influence of metal ions $\left(\mathrm{Al}^{3+}, \mathrm{Cr}^{3+}, \mathrm{Fe}^{3+}, \mathrm{Co}^{2+}, \mathrm{Mg}^{2+}\right.$ and $\mathrm{Ni}^{2+}$ ) on the behavior of the bacterial strain in the concentration range from $10^{-3}$ to $10^{-6} \mathrm{~mol} / \mathrm{L}$. Bacterial samples were characterized by infra-red spectroscopy - Fourier transform Infra-red (FTIR). The isoelectric point (IEP) of the bacterium $R$. ruber was obtained by analysis of zeta potential. The results showed an IEP at $\mathrm{pH}=2.4$ to strain in nature, in the other hand the IEP of activated strain $(0.1 \mathrm{M} \mathrm{NaOH})$ was not observed. Bacterial surface-active strain showed slightly more negative than the surface of the bacterium in nature. All samples demonstrated changes in $\mathrm{pH}$ zeta potential during bacterial interaction with the analyzed ions. Samples remained negatively charged at the $\mathrm{pH}$ studied to all cations except $\mathrm{Fe}^{3+}$. Finally, it's believed that the bacterium Rhodococcus ruber is a viable option for the treatment of metal contaminated wastewater.

\section{Keywords}

Liquids effluents; Heavy metals; Rhodococcus ruber; Zeta potential. 


\section{Sumário}

$\begin{array}{ll}1 . & 17\end{array}$

2. Objetivos 20

2.1. Objetivo geral 20

2.2. Objetivos específicos 20

3. Revisão Bibliográfica 21

3.1. Metais no meio aquoso 21

3.1.1. Níquel (Ni) 21

3.1.2. Cobalto (Co) 22

3.1.3. Magnésio $(\mathrm{Mg}) \quad 23$

3.1.4. Alumínio (Al) 23

3.1.5. Cromo $(\mathrm{Cr}) \quad 24$

3.1.6. Ferro (Fe) 25

3.2. Métodos de Remoção de Metais 25

3.2.1. Biossorção 26

3.2.1.1. Mecanismos de Ligação 27

3.2.2. Adsorção 28

3.3. Potenciais Biossorventes 30

3.3.1. Bactérias 31

3.3.2. Estirpe Rhodococcus 34

3.3.3. Estirpe Rhodococcus ruber 35

3.4. Dupla Camada Elétrica 35

3.5. Potencial Zeta 38

3.6. Infra-vermelho 40

4. Materiais e Métodos 42

4.1. Preparo da biomassa 42

4.1.1. Ativação da biomassa com $\mathrm{NaOH} 43$

4.2. Preparo das soluções estoques dos 43

diferentes íons metálicos

4.2.1. Solução de Alumínio 43 
4.2.2. Solução de Cobalto 43

4.2.3. Solução de Cromo 44

4.2.4. Solução de Ferro 44

4.2.5. Solução de Magnésio 44

4.2.6. Solução de Níquel 44

4.2.7. Soluções para ajuste de $\mathrm{pH} \quad 44$

4.3. Diagramas de Especiação 44

4.4. Medidas de Potencial Zeta 45

4.4.1. Curvas Bacterianas 45

4.4.2. Curvas da Biomassa com metal 46

4.5. Espectroscopia de Infra-vermelho 46

4.5.1. Espectroscopia das biomassas 47

4.5.2. Espectroscopia da biomassa com metal 47

5. Resultados e Discussão 48

5.1. Diagrama Termodinâmico de Especiação Química 48

5.1.1. Especiação química do Níquel 48

5.1.2. Reações de hidrólise do Cobalto 50

5.1.3. Reações de hidrólise do Magnésio 53

5.1.4. Reações de hidrólise do Alumínio 55

5.1.5. Reações de hidrólise do Cromo 57

5.1.6. Reações de hidrólise do Ferro 59

5.2. Potencial Zeta 61

5.2.1. Potencial zeta das biomassas 62

5.2.2. Efeito da concentração bacteriana após a interação 64 metálica nas medidas do Potencial Zeta

5.2.3. Efeito da concentração metálica nas medidas do 67 Potencial Zeta

5.2.4. Potencial Zeta das interações bacterianas com os íons 74 metálicos

5.2.4.1. Níquel (II) $\quad 74$

5.2.4.2. Cobalto (II) 75

5.2.4.3. Magnésio (II) $\quad 77$

5.2.4.4. Alumínio (III) 79

$\begin{array}{lll}\text { 5.2.4.5. } & \text { Cromo (III) } & 81\end{array}$ 
5.2.4.6. Ferro (III) 83

5.3. Espectroscopia de Infra-vermelho 86

5.3.1. Espectros das biomassas 86

5.3.2. Espectros das interações bacterianas com os íons 88 metálicos

5.3.2.1. Níquel (II) $\quad 89$

5.3.2.2. Cobalto (II) $\quad 92$

5.3.2.3. Magnésio (II) 95

5.3.2.4. Alumínio (III) 98

5.3.2.5. Cromo (III) 102

5.3.2.6. Ferro (III) 106

6. Conclusão 110

7. Referências Bibliográficas 112 


\section{Lista de Figuras}

Figura1. Classificação do mecanismo de biossorção: dependência do metabolismo celular.

Figura 2. Classificação do mecanismo de biossorção: sítio onde o metal é removido.

Figura 3. Esquema da estrutura celular de bactérias gram-positivas (Volesky, 2007).

Figura 4. Esquema da estrutura celular de bactérias gram-negativas (Volesky, 2007).

Figura 5. Dupla Camada Elétrica de Helmholtz e Perrin

36

Figura 6. Dupla Camada Elétrica de Gouy - Chapman 37

Figura 7. Modelo de Stern. (Adaptado Pino, 2007). 38

Figura 8. Diagrama de hidrólise do níquel, em solução aquosa, considerando a concentração de $10^{-3} \mathrm{M}$.

Figura 9. Diagrama de hidrólise do níquel, em solução aquosa, considerando a concentração de $10^{-4} \mathrm{M}$.

Figura 10. Diagrama de hidrólise do níquel, em solução aquosa, considerando a concentração de $10^{-5} \mathrm{M}$.

Figura 11. Diagrama de hidrólise do níquel, em solução aquosa, considerando a concentração de $10^{-6} \mathrm{M}$.

Figura 12. Diagrama de hidrólise do cobalto, em solução aquosa, considerando a concentração $10^{-3} \mathrm{M}$.

Figura 13. Diagrama de hidrólise do cobalto, em solução aquosa, considerando a concentração $10^{-4} \mathrm{M}$.

Figura 14. Diagrama de hidrólise do cobalto, em solução aquosa, considerando a concentração $10^{-5} \mathrm{M}$.

Figura 15. Diagrama de hidrólise do cobalto, em solução aquosa, considerando a concentração $10^{-6} \mathrm{M}$.

Figura 16. Diagrama de hidrólise do magnésio, em solução aquosa, considerando a concentração de $10^{-3} \mathrm{M}$.

Figura 17. Diagrama de hidrólise do magnésio, em solução aquosa, considerando a concentração de $10^{-4} \mathrm{M}$.

Figura 18. Diagrama de hidrólise do magnésio, em solução aquosa, considerando a concentração de $10^{-5} \mathrm{M}$.

Figura 19. Diagrama de hidrólise do magnésio, em solução aquosa, considerando a concentração de $10^{-6} \mathrm{M}$. 
Figura 20. Diagrama de hidrólise do alumínio, em solução aquosa, concentração $10^{-4} \mathrm{M}$.

Figura 21. Diagrama de especiação do alumínio, em solução aquosa, na concentração $10^{-5} \mathrm{M}$.

Figura 22. Diagrama de especiação do alumínio, em solução aquosa concentração $10^{-6} \mathrm{M}$.

Figura 23. Diagrama de hidrólise do cromo, em solução aquosa, para a concentração $10^{-4} \mathrm{M}$.

Figura 24. Diagrama de hidrólise do cromo, em solução aquosa, para 58 a concentração $10^{-5} \mathrm{M}$.

Figura 25. Diagrama de especiação do cromo, em solução aquosa, para a concentração $10^{-6} \mathrm{M}$.

Figura 26. Diagrama de hidrolise do ferro, em solução aquosa, concentração $10^{-4} \mathrm{M}$.

Figura 27. Diagrama de hidrolise do ferro, em solução aquosa, concentração $10^{-5} \mathrm{M}$.

Figura 28. Diagrama de hidrolise do ferro, em solução aquosa, concentração $10^{-6} \mathrm{M}$.

Figura 29. Curvas de Potencial Zeta da estirpe R. Ruber in natura, na presença de $\mathrm{KCl}$, em função do $\mathrm{pH}$.

Figura 30. Curvas de Potencial zeta da estirpe $R$. ruber ativada, na presença de $\mathrm{KCl}$, em função do $\mathrm{pH}$.

Figura 31. Efeitos da concentração bacteriana no potencial zeta.

Figura 32. Imagem do potencial zeta da $R$. ruber na concentração de 100 ppm.

Figura 33. Potencial Zeta da bactéria in natura na presença de níquel.

Figura 34. Potencial Zeta da bactéria ativada na presença de níquel.

68

Figura 35. Potencial Zeta da bactéria in natura na presença de cobalto.

Figura 36. Potencial Zeta da bactéria ativada na presença de cobalto. 69

Figura 37. Potencial Zeta da bactéria in natura na presença de magnésio.

Figura 38. Potencial Zeta da bactéria ativada na presença de magnésio.

Figura 39. Potencial Zeta da bactéria in natura na presença de alumínio.

Figura 40. Potencial Zeta da bactéria ativada na presença de alumínio. 
Figura 41. Potencial Zeta da bactéria in natura na presença de cromo.

Figura 42. Potencial Zeta da bactéria ativada na presença de cromo. 72

Figura 43. Potencial Zeta da bactéria in natura na presença de ferro. 73

Figura 44. Potencial Zeta da bactéria ativada na presença de ferro. 73

Figura 45. Potencial Zeta do R. ruber in natura antes e após 75 interação com o níquel; concentração de eletrólito indiferente de $10^{-3}$ $\mathrm{M}$ de $\mathrm{KCl}$.

Figura 46. Potencial Zeta do $R$. ruber ativada antes e após interação com o níquel; concentração de eletrólito indiferente de $10^{-3} \mathrm{M}$ de $\mathrm{KCl}$.

Figura 47. Potencial Zeta do R. ruber in natura antes e após

interação com o cobalto; concentração de eletrólito indiferente de $10^{-3}$ $\mathrm{M}$ de $\mathrm{KCl}$.

Figura 48. Potencial Zeta do $R$. ruber ativada antes e após interação com o cobalto; concentração de eletrólito indiferente de $10^{-3} \mathrm{M}$ de $\mathrm{KCl}$.

Figura 49. Potencial Zeta do R. ruber in natura antes e após interação com o magnésio; concentração de eletrólito indiferente de $10^{-3} \mathrm{M}$ de $\mathrm{KCl}$.

Figura 50. Potencial Zeta do R. Ruber ativada antes e após interação com o magnésio; concentração de eletrólito indiferente de $10^{-3} \mathrm{M}$ de $\mathrm{KCl}$.

Figura 51. Potencial Zeta do R. ruber in natura antes e após interação com o alumínio; concentração de eletrólito indiferente de $10^{-3} \mathrm{M}$ de $\mathrm{KCl}$.

Figura 52. Potencial Zeta do R. Ruber ativada antes e após interação com o alumínio; concentração de eletrólito indiferente de $10^{-3} \mathrm{M}$ de $\mathrm{KCl}$.

Figura 53. Potencial Zeta do R. ruber in natura antes e após interação com o cromo; concentração de eletrólito indiferente de $10^{-3}$ $\mathrm{M}$ de $\mathrm{KCl}$.

Figura 54. Potencial Zeta do $R$. ruber ativada antes e após interação com o cromo; concentração de eletrólito indiferente de $10^{-3} \mathrm{M}$ de $\mathrm{KCl}$.

Figura 55. Potencial Zeta do R. ruber in natura antes e após interação com o ferro; concentração de eletrólito indiferente de $10^{-3} \mathrm{M}$ de $\mathrm{KCl}$.

Figura 56. Potencial Zeta do R. Ruber ativada antes e após interação com o ferro; concentração de eletrólito indiferente de $10^{-3} \mathrm{M}$ de $\mathrm{KCl}$.

Figura 57. Espectro de FTIR para $R$. ruber in natura.

Figura 58. Espectro de FTIR para R. ruber ativada.

Figura 59. Espectros de FTIR para R. ruber in natura e ativada. 
Figura 60. Espectros de FTIR para $R$. ruber in natura antes e depois da interação com o níquel.

Figura 61. Espectros ampliados de FTIR da R. Ruber in natura antes e depois da interação com o níquel, intervalo entre os comprimentos de onda entre 4000 e $2000 \mathrm{~cm}^{-1}$.

Figura 62. Espectros ampliados de FTIR da R. Ruber in natura antes e depois da interação com o níquel, intervalo entre os comprimentos de onda entre 2000 e $400 \mathrm{~cm}^{-1}$.

Figura 63. Espectros de FTIR para R. ruber ativada antes e depois da interação com o níquel.

Figura 64. Espectros ampliados de FTIR da R. Ruber ativada antes e depois da interação com o níquel, intervalo entre os comprimentos de onda entre $4000 \mathrm{~cm}^{-1}$ e $2000 \mathrm{~cm}^{-1}$.

Figura 65. Espectros ampliados de FTIR da $R$. Ruber ativada antes e depois da interação com o níquel, intervalo entre os comprimentos de onda entre $2000 \mathrm{~cm}^{-1}$ e $400 \mathrm{~cm}^{-1}$.

Figura 66. Espectros de FTIR para $R$. ruber in natura antes e depois da interação com o cobalto.

Figura 67. Espectros ampliados de FTIR da R. Ruber in natura e depois da interação com o cobalto, intervalo entre os comprimentos de onda $4000 \mathrm{~cm}^{-1}$ e $2000 \mathrm{~cm}^{-1}$.

Figura 68. Espectros ampliados de FTIR da R. Ruber in natura e depois da interação com o cobalto, intervalo entre os comprimentos de onda $2000 \mathrm{~cm}^{-1}$ e $400 \mathrm{~cm}^{-1}$.

Figura 69. Espectros de FTIR para $R$. ruber ativada antes e depois da interação com o cobalto.

Figura 70. Espectros ampliados de FTIR da R. Ruber ativada e depois da interação com o cobalto, intervalo entre os comprimentos de onda $4000 \mathrm{~cm}^{-1}$ e $2000 \mathrm{~cm}^{-1}$.

Figura 71. Espectros ampliados de FTIR da R. Ruber ativada e depois da interação com o cobalto, intervalo entre os comprimentos de onda $2000 \mathrm{~cm}^{-1}$ e $400 \mathrm{~cm}^{-1}$.

Figura 72. Espectros de FTIR para R. ruber in natura antes e depois da interação com o magnésio.

Figura 73. Espectros de FTIR para R. ruber ativada antes e depois da interação com o magnésio.

Figura 74. Espectros ampliados de FTIR da R. Ruber in natura e depois da interação com o magnésio, intervalo entre os comprimentos de onda $4000 \mathrm{~cm}^{-1}$ e $2000 \mathrm{~cm}^{-1}$. 
Figura 75. Espectros ampliados de FTIR da R. Ruber in natura e depois da interação com o magnésio, intervalo entre os comprimentos de onda $2000 \mathrm{~cm}^{-1}$ e $400 \mathrm{~cm}^{-1}$.

Figura 76. Espectros ampliados de FTIR da R. Ruber in natura e depois da interação com o magnésio, intervalo entre os comprimentos de onda $4000 \mathrm{~cm}^{-1}$ e $2000 \mathrm{~cm}^{-1}$.

Figura 77. Espectros ampliados de FTIR da $R$. Ruber in natura e depois da interação com o magnésio, intervalo entre os comprimentos de onda $2000 \mathrm{~cm}^{-1}$ e $400 \mathrm{~cm}^{-1}$.

Figura 78. Espectros de FTIR para $R$. ruber in natura antes e depois da interação com o alumínio.

Figura 79. Espectros ampliados de FTIR da R. Ruber in natura e 100 depois da interação com o magnésio, intervalo entre os comprimentos de onda $4000 \mathrm{~cm}^{-1}$ e $2000 \mathrm{~cm}^{-1}$.

Figura 80. Espectros ampliados de FTIR da R. Ruber in natura e 100 depois da interação com o magnésio, intervalo entre os comprimentos de onda $2000 \mathrm{~cm}^{-1}$ e $400 \mathrm{~cm}^{-1}$.

Figura 81. Espectros de FTIR para R. ruber ativada antes e depois da 101 interação com o alumínio.

Figura 82. Espectros ampliados de FTIR da R. Ruber in natura e 102 depois da interação com o alumínio, intervalo entre os comprimentos de onda $4000 \mathrm{~cm}^{-1}$ e $2000 \mathrm{~cm}^{-1}$.

Figura 83. Espectros ampliados de FTIR da R. Ruber in natura e 102 depois da interação com o alumínio, intervalo entre os comprimentos de onda $2000 \mathrm{~cm}^{-1}$ e $400 \mathrm{~cm}^{-1}$.

Figura 84. Espectros de FTIR para R. ruber in natura antes e depois da interação com o cromo.

Figura 85. Espectros ampliados de FTIR da R. Ruber in natura e depois da interação com o cromo, intervalo entre os comprimentos de onda $4000 \mathrm{~cm}^{-1}$ e $2000 \mathrm{~cm}^{-1}$.

Figura 86. Espectros ampliados de FTIR da R. Ruber in natura e 104 depois da interação com o cromo, intervalo entre os comprimentos de onda $2000 \mathrm{~cm}^{-1}$ e $400 \mathrm{~cm}^{-1}$.

Figura 87. Espectros de FTIR para $R$. ruber ativada antes e depois da interação com o cromo.

Figura 88. Espectros ampliados de FTIR da R. Ruber in natura e 105 depois da interação com o cromo, intervalo entre os comprimentos de onda $4000 \mathrm{~cm}^{-1}$ e $2000 \mathrm{~cm}^{-1}$.

Figura 89. Espectros ampliados de FTIR da R. Ruber in natura e 106 depois da interação com o cromo, intervalo entre os comprimentos de onda $2000 \mathrm{~cm}^{-1}$ e $400 \mathrm{~cm}^{-1}$. 
Figura 90. Espectros de FTIR para R. ruber in natura antes e depois da interação com o ferro.

Figura 91. Espectros ampliados de FTIR da R. Ruber in natura e depois da interação com o ferro, intervalo entre os comprimentos de onda $4000 \mathrm{~cm}^{-1}$ e $2000 \mathrm{~cm}^{-1}$.

Figura 92. Espectros ampliados de FTIR da R. Ruber in natura e depois da interação com o ferro, intervalo entre os comprimentos de onda $2000 \mathrm{~cm}^{-1}$ e $400 \mathrm{~cm}^{-1}$.

Figura 93. Espectros de FTIR para R. ruber ativada antes e depois da 108 interação com o ferro.

Figura 94. Espectros ampliados de FTIR da R. Ruber in natura e depois da interação com o ferro, intervalo entre os comprimentos de onda $4000 \mathrm{~cm}^{-1}$ e $2000 \mathrm{~cm}^{-1}$.

Figura 95. Espectros ampliados de FTIR da R. Ruber in natura e depois da interação com o ferro, intervalo entre os comprimentos de onda $2000 \mathrm{~cm}^{-1}$ e $400 \mathrm{~cm}^{-1}$. 


\section{Lista de tabelas}

Tabela 1. Fontes de Exposição Ambiental do Cobalto 22

Tabela 2. Limites Máximos Aceitáveis de Alguns Metais 25 em água segundo CONAMA 357/05

Tabela 3. Grupos químicos de ligação envolvidos na 32 biossorção.

Tabela 4. Valores de PIE para diferentes espécies de $\quad 40$ bactérias (Rijnaarts et al., 1995).

Tabela 5. Concentrações de pH utilizados nas análises de $\quad 44$ Infra-vermelho.

Tabela 6. Faixa de $\mathrm{pH}$ com maior predominância de $\mathrm{Ni}^{2+} \quad 50$

Tabela 7. Faixa de $\mathrm{pH}$ com maior predominância de $\mathrm{Co}^{2+} \quad 53$

Tabela 8. Faixa de pH com maior predominância de $\mathrm{Mg}^{2+} \quad 55$

0 $\quad$ Tabela 9. Faixa de pH com maior predominância de $\mathrm{Al}^{3+} \quad 57$

Tabela 10. Faixa de pH com maior predominância de $\mathrm{Cr}^{3+} \quad 59$

Tabela 11. Faixa de pH com maior predominância de $\mathrm{Fe}^{3+} \quad 61$

Tabela 12. Resumo das faixas ideais de $\mathrm{pH} \quad 61$

Tabela 13. Valores de desvio padrão da $R$. ruber nas 63 concentrações 50ppm e 75ppm.

Tabela 14. Bandas de absorção IR e possíveis grupos 86 correspondentes. 